\title{
Parametric analysis of thermal losses on hybrid solar gas-turbine power plants
}

\author{
R.P. Merchán ${ }^{1}$, M.J. Santos ${ }^{1}$, A. Medina ${ }^{1}$ and A. Calvo Hernández ${ }^{1}$ \\ ${ }^{1}$ Department of Applied Physics \\ Facultad de Ciencias - University of Salamanca \\ Plaza de la Merced, s/n, 37071 Salamanca (Spain)
}

Phone/Fax number:+0034 923 294436, e-mail: rpmerchan@usal.es, smjesus@ usal.es, $\underline{\text { amd385@ usal.es, anca@ usal.es }}$

\begin{abstract}
In this paper a parametric analysis of thermal and pressure losses for a hybrid Brayton thermosolar plant is carried out. A serial hybridization is modelled with the purpose of delivering an stable power output. A purely thermodynamic model describing this sort of facilities is presented. The model is general and flexible, so it is easily applicable to different plant configurations (hybrid or pure combustion modes). The overall system is considered as formed by three subsystems linked by heat exchangers: solar collector, combustion chamber, and recuperative Brayton gas-turbine. All the main irreversibility sources existing in real installations are assumed by the subsystem models. For numerical calculations, particular parameters from a real installation and actual meteorological data are taken (solar irradiance and ambient temperature are yearly averaged). Later, a sensitivity analysis is accomplished, in which both solar and turbine subsystems are examined, being the optical efficiency of the heliostat field and the turbine efficiency, respectively, the most influential variables. This kind of studies could be a guideline for the design of future hybrid gas-turbine thermosolar facilities.
\end{abstract}

\section{Key words}

Thermosolar gas turbines, hybrid plants, thermal losses, sensitivity analysis.

\section{Nomenclature}

\begin{tabular}{|c|c|}
\hline$A_{a}$ & aperture area of the collector \\
\hline$C$ & solar collector concentration ratio \\
\hline$f$ & solar share \\
\hline$G$ & direct solar irradiance \\
\hline$\dot{m}_{f}$ & fuel mass flow rate \\
\hline$P$ & power output \\
\hline & pressure at compressor exit \\
\hline & heat losses at the combustion chamber \\
\hline$\dot{Q}_{\text {ine }}$ & $\begin{array}{l}\text { heat losses at the heat exchanger associated to the } \\
\text { combustion chamber }\end{array}$ \\
\hline & heat rate input from the combustion chamber \\
\hline & heat rate input from the solar collector \\
\hline & heat losses at the solar receiver \\
\hline$\left|\hat{Q}_{1}\right|$ & $\begin{array}{l}\text { losses associated to heat transfers in the solar field } \\
\text { heat-transfer rate between the working fluid and the }\end{array}$ \\
\hline
\end{tabular}

ambient

$Q_{\text {INY }} \quad$ lower heating value of the fuel

$\mid Q_{0} \| \quad$ optical losses at the solar subsystem

$r_{e} \quad$ fuel conversion rate

$T_{H S} \quad$ working temperature of the solar collector

$T_{L} \quad$ ambient temperature

$U_{L} \quad$ effective conduction-convection heat transfer losses coefficient

$\Delta p_{H} \quad$ pressure drops in the heat input

$\alpha \quad$ effective emissivity of the solar collector

$\eta \quad$ overall thermal efficiency

$\eta_{C} \quad$ combustion chamber efficiency

$\eta_{H} \quad$ thermal efficiency of the Brayton heat engine

$\eta s \quad$ solar collector efficiency

no optical efficiency

$\varepsilon_{\mathrm{HC}} \quad$ combustion chamber heat exchanger effectiveness

$\varepsilon H S \quad$ solar collector heat exchanger effectiveness

$\varepsilon_{c} \quad$ isentropic efficiency of the compressor

$\varepsilon_{\mathrm{r}} \quad$ recuperator effectiveness

$\varepsilon_{\mathrm{t}} \quad$ isentropic efficiency of the turbine

$\sigma \quad$ Stefan-Boltzmann constant

\section{Introduction}

The necessity to diversify the energy sources in power generation and to look for renewable ones is undoubted. Thermosolar power plants, which constitute one of the main ways of solar energy exploitation, are competing with other renewable energy sources for generating clean electrical energy, reducing fuel consumption. Hybrid thermosolar plants combine two great advantages on electricity generation: the emissions reduction of thermosolar energy, as well as the stable supply of power output to the grid of conventional power plants, avoiding the use of storage systems. For those reasons in the last years a big effort has been done in the development of prototypes and experimental plants in order to investigate the viability of thermosolar hybrid Brayton cycle plants.

A working fluid, usually air, is preheated by concentration solar energy, before entering a combustion chamber. Then, the fluid performs a thermodynamic cycle (in this case, a Brayton cycle), generating electrical energy indirectly. In this way fossil fuel and the associated emissions are reduced. It is important to note 
that apart from being easily scalable, gas-turbines can be combined with other cycles like bottoming Rankine. Also they do not require too much water for operation, which makes them suitable for electrical generation in arid regions, and are extremely versatile [1].

Experimental projects and prototypes developed up to date show that this technology is viable, but they also reveal that it is necessary to improve their efficiency, in order to generate electricity at competitive prices. Apart from $\mathrm{R}+\mathrm{D}$ projects, prototypes, and experimental installations, several research works have been published in the last times. Some of them make use of commercial simulation environments, which allow a detailed description of all plant components and specific calculations on the solar subsystem. However, it is not easy to extract direct physical information about the main losses sources in the plant and to perform a global optimization of the plant design. Because of this reason, in this paper the next modus operandi is followed instead of this one.

A second type of strategy is to build a theoretical model of the plant, in terms of a reduced number of parameters, allowing a simple but realistic picture of plant operation and to estimate its performance records. Thermodynamic analyses can provide an integrated point of view of all subsystems and their importance in the overall efficiency. Moreover, they help to predesign future generations of plants based in this concept because their flexibility to survey the adequate intervals of key parameters for optimal plant operation.

There are several theoretical works that start from the ideal Brayton cycle and thereafter refinements are included in the analysis of the thermodynamics of the cycle in order to recover realistic output records. Usually, in these works, the model for the concentrated solar subsystem, although including the main heat transfer losses, is simple. This allows to obtain closed analytical expressions for thermal efficiencies and power output, and then check the model predictions for particular design point conditions, with fixed values of direct solar irradiance and ambient temperature. And in a possible step forward to suggest and guide optimization strategies.

\section{Thermodynamic model}

The thermodynamic model employed in this paper is the same recently proposed in Olivenza et al.'s [2] and in [3] for hybrid Brayton thermosolar plants. These plants have three main elements: the heliostat field, the receiver, and the power conversion system. The model, in which refers to the thermodynamic cycle, starts from a closed Brayton cycle however incorporating the main losses and irreversibility sources: pressure decays, non-ideal compressor and turbine, heat transfer losses in the solar collector, combustion inefficiencies, heat exchangers, etc.

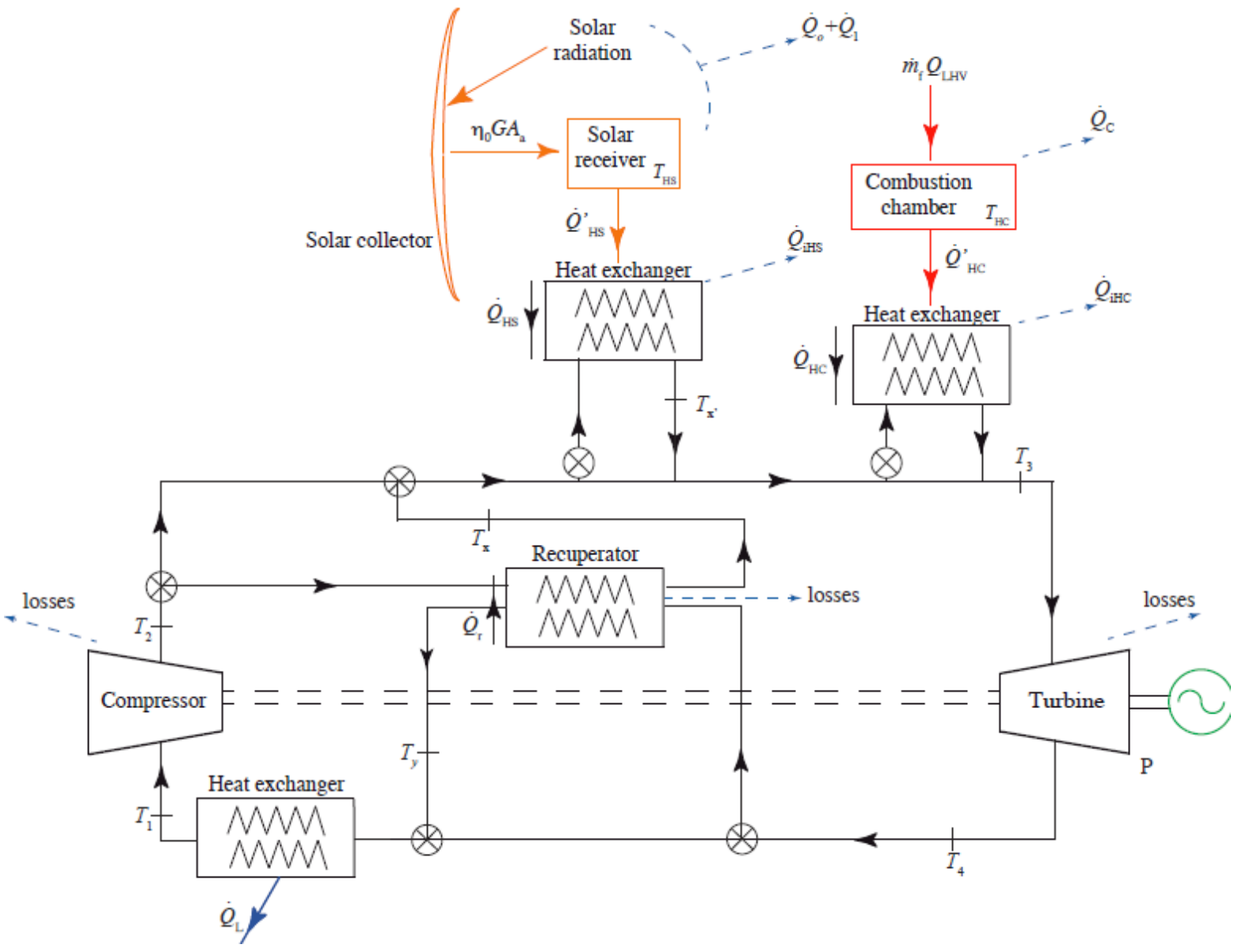

Fig. 1. Scheme of the hybrid solar Brayton plant considered. The main heat transfers and temperatures are shown. Also the key losses sources considered in the model are depicted. 
A central tower hybrid solar thermal installation, as depicted in Fig. 1, is considered. The whole system receives two energy inputs. On one hand, a heat input, $\mathrm{GA}_{\mathrm{a}}$, coming from the sun, where $\mathrm{G}$ is the direct solar irradiance and $A_{a}$, the aperture area of the solar field. For the solar subsystem, a simple model, which accounts heat losses in the solar collector due to radiation and conduction/convection terms, was supposed.

$$
\eta_{s}=\eta_{0}-\frac{1}{G C}\left[\alpha \sigma\left(T_{H S}^{4}-T_{L}^{4}\right)+U_{L}\left(T_{H S}-T_{L}\right)\right]
$$

Being $\eta_{s}$ the solar collector efficiency, $\eta_{0}$ the optical efficiency, $\mathrm{C}$ the concentration ratio, $\alpha$ the effective emissivity of the collector, $\sigma$ the Stefan-Boltzmann constant, $\mathrm{T}_{\mathrm{HS}}$ the collector working temperature, $\mathrm{T}_{\mathrm{L}}$ the ambient temperature and $\mathrm{U}_{\mathrm{L}}$ the convective heat loss coefficient. In Fig. $1, \phi_{0}$ denotes the optical losses, $\phi_{1}$ losses associated to the heat transfers, $\phi_{\text {ims }}$ losses on the solar receiver and $\phi_{H S}$ refers to the heat rate input from the solar collector.

On other hand, the energy input at the combustion chamber is $\dot{\mathrm{m}}_{\mathrm{f}} \mathrm{Q}_{\mathrm{LHV}}$, being $\dot{\mathrm{m}}_{\mathrm{f}}$ the fuel mass flow rate and $Q_{\text {LHV }}$ its corresponding lower heating value. $\phi_{C}$ is related with the heat losses in combustion subsystem, $\phi_{\text {iHC }}$ refers to the heat losses at its heat exchanger and $Q_{\text {HC }}$ is the heat rate input from combustion chamber.

Finally, the heat engine generates a mechanical power output, $\mathrm{P}$, and releases a heat flux to the ambient, $\phi_{L}$.
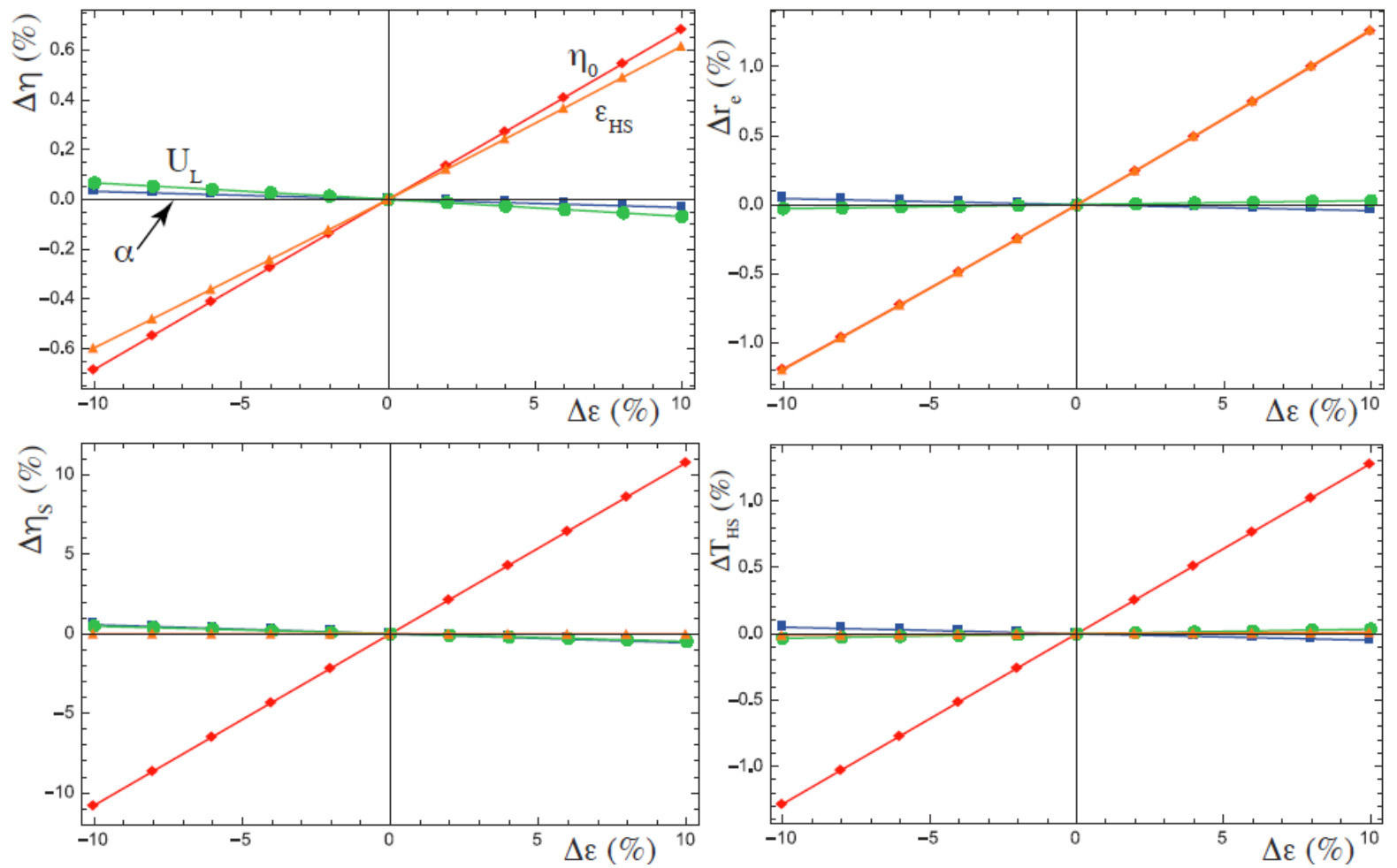

Fig. 2. Sensitivity of different output records, overall thermal efficiency $(\eta)$, fuel conversion efficiency $\left(r_{e}\right)$, solar subsystem efficiency $(\eta \mathrm{s})$, and working temperature of the solar receiver $\left(\mathrm{T}_{\mathrm{HS}}\right)$, to several irreversibility parameters of the solar subsystem (denoted in general as $\Delta \varepsilon$ ): optical efficiency $\left(\eta_{0}\right)$, effective convective losses coefficient $\left(\mathrm{U}_{\mathrm{L}}\right)$, effective emissivity $(\alpha)$, and solar heat exchanger effectiveness $(\varepsilon \mathrm{HS})$. Both axis are represented in relative terms as percentages. The central point is related to the yearly averages of the recuperative plant at real operating conditions. 

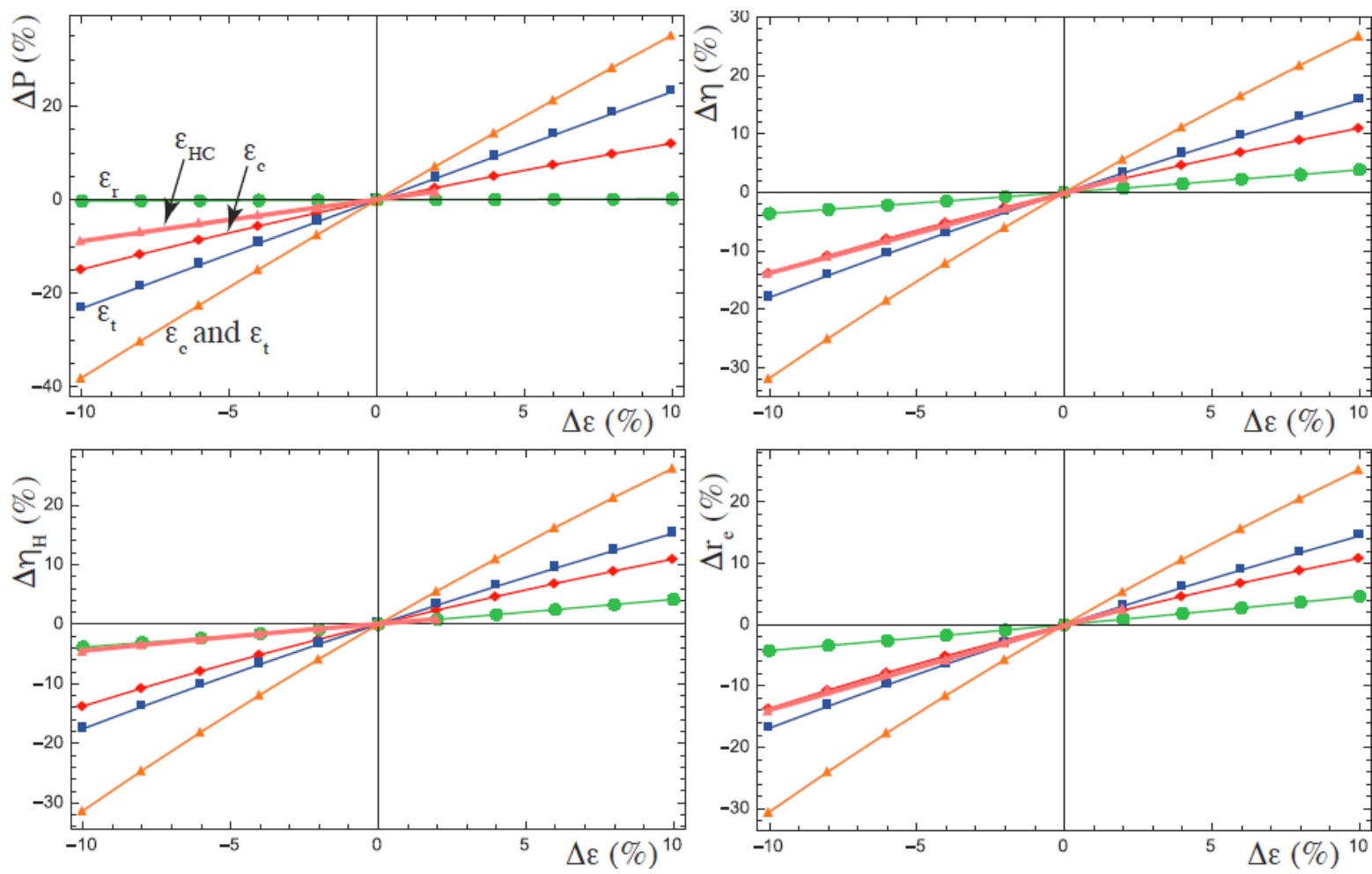

Fig. 3. Sensitivity of different output records, power output $(P)$, overall thermal efficiency $(\eta)$, Brayton cycle efficiency $\left(\eta_{H}\right)$, and fuel conversion efficiency $\left(\mathrm{r}_{\mathrm{e}}\right)$, to several irreversibility parameters of the heat engine: isentropic efficiency of the turbine $\left(\varepsilon_{t}\right)$, isentropic efficiency of the compressor $\left(\varepsilon_{c}\right)$, recuperator effectiveness $\left(\varepsilon_{\mathrm{r}}\right)$, and effectiveness of the heat exchanger associated to the combustion chamber $\left(\varepsilon_{\mathrm{HC}}\right)$. Another case is also considered: when $\varepsilon_{\mathrm{c}}$ and $\varepsilon_{\mathrm{t}}$ are simultaneously changed in the same way. Both axis are represented in relative terms as percentages. The central point is related to the yearly averages of the recuperative plant at real operating conditions.

\section{A. Sensitivity to solar subsystem}

Figure 2 shows the influence of the main irreversibility sources in the solar subsystem: optical efficiency $\left(\eta_{0}\right)$, heat transfer losses parameters $\left(\mathrm{U}_{\mathrm{L}}\right.$ and $\alpha$ ), and solar heat exchanger effectiveness $\left(\varepsilon_{\mathrm{HS}}\right)$. In the horizontal axis relative deviations of losses parameters with respect to yearly averaged actual operating conditions are plotted, taking values up to $\pm 10 \%$; whereas the vertical axis refers to relative deviations for overall thermal efficiency $(\Delta \eta)$, fuel conversion rate $\left(\Delta r_{e}\right)$, solar collector efficiency $\left(\Delta \eta_{\mathrm{S}}\right)$, and effective receiver working temperature $\left(\Delta \mathrm{T}_{\mathrm{HS}}\right)$. It is noteworthy that evolutions are almost linear in all cases.

Numerical variations on the overall efficiency are small in any case, but $\eta$ shows more sensitivity to optical efficiency $\left(\eta_{0}\right)$ and heat transfer from the receiver to the working fluid $\left(\varepsilon_{\mathrm{HS}}\right)$ than to radiation or conductionconvection heat losses $\left(\mathrm{U}_{\mathrm{L}}\right.$ and $\left.\alpha\right)$.

An increment of $10 \%$ on $\eta_{0}$ will result on a change of about $10 \%$ on $\eta_{S}$, although this only will improve $0.6 \%$ the overall thermal efficiency, $\eta$, and $1.5 \%$ the fuel conversion rate, $r_{e}$. That is to say, a substantial improvement on the efficiency of the solar subsystem would be slightly reflected on the fuel conversion efficiency and poorly on the overall plant efficiency, which constitutes one of the main conclusions of the predictions of this thermodynamic model.

\section{B. Sensitivity to heat engine}

In contrast to previous case, sensitivity to changes on the losses parameters associated to the heat engine will greatly affect plant performance, as it is surveyed in Fig. 3 . In this case, the evolution of all variables is also almost linear, however the scales of the vertical axes indicate much more important variations on the performance records. For example, an increment of $10 \%$ on compressor isentropic efficiency, $\varepsilon_{\mathrm{c}}$, will lead to $10 \%$ rise on power output and the same increment on turbine isentropic efficiency, $\varepsilon_{t}$, to more than $20 \%$ on P. Great improvements are achieved when both the compressor and turbine efficiency are incremented simultaneously, almost $40 \%$ on power output can be reached if $\varepsilon_{\mathrm{c}}+\varepsilon_{\mathrm{t}}$ rises up to $10 \%$. As regeneration is an internal process of the heat engine, recuperator effectiveness changes would not have any influence on power output, nevertheless other output records would be affected. The other analyzed output records (overall efficiency, $\eta$, Brayton subsystem efficiency, $\eta_{\mathrm{H}}$, and fuel conversion rate would, $\mathrm{r}_{\mathrm{e}}$ ) change in the interval $[-30 \%,+30 \%]$ for variations in the losses coefficients of the power unit in the interval [-10\%, $+10 \%$ ]. In short, reductions on Brayton losses would be increased by a factor 3 on the plant records.

\section{C. $\quad$ Sensitivity to pressure losses}

Similarly, in Fig. 4 the plant sensitivity to the relative pressure decays with respect to the pressure at the compressor exit, $\Delta \mathrm{p}_{\mathrm{H}} / \mathrm{p}_{\mathrm{H}}$, is plotted in the $x$-axis (see Fig. 


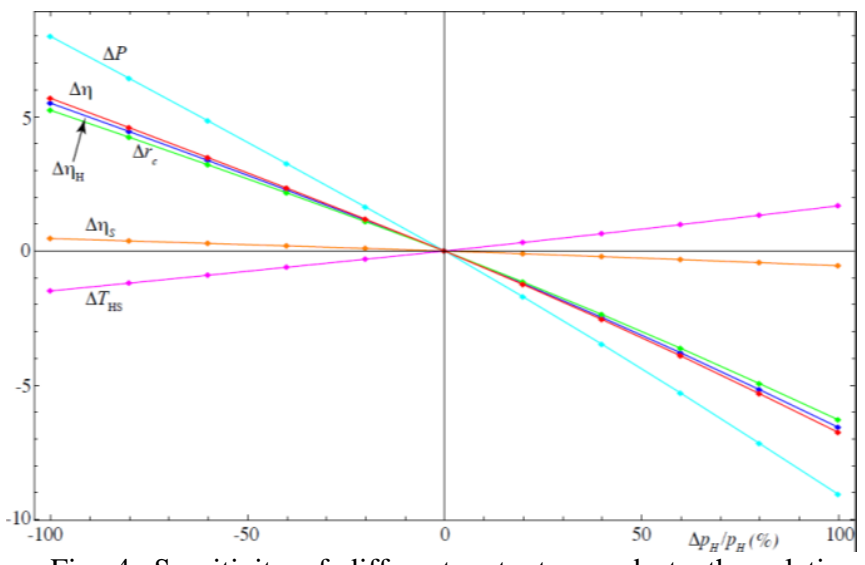

Fig. 4. Sensitivity of different output records to the relative pressure decay in the hot side of the Brayton cycle, $\Delta \mathrm{pH} / \mathrm{pH}$. Both axis are represented in relative terms as percentages. The central point is related to the yearly averages of the recuperative plant at real operating conditions.
2 of [3]). This pressure decay is being characterized by a single parameter in spite that in real installations decays occur in several steps. When real operating conditions are supposed, the pressure decay is about $9.2 \%$. Moreover, if no pressure decay is assumed, power output will improve $8 \%$, and fuel conversion rate and overall thermal efficiency approximately $6 \%$. On the contrary, when higher pressure losses are considered, plant operation would be decreased. In fact, pressure losses about $18 \%$ would worsen power output about $10 \%$ and overall thermal efficiency 7\%. As deduced from Fig. 4, performance variables do display a parabolic behavior further from linear of that shown in former figures. Additionally, variations in pressure losses have an appreciable effect on the working temperature of the solar receiver and so, on the solar subsystem efficiency.
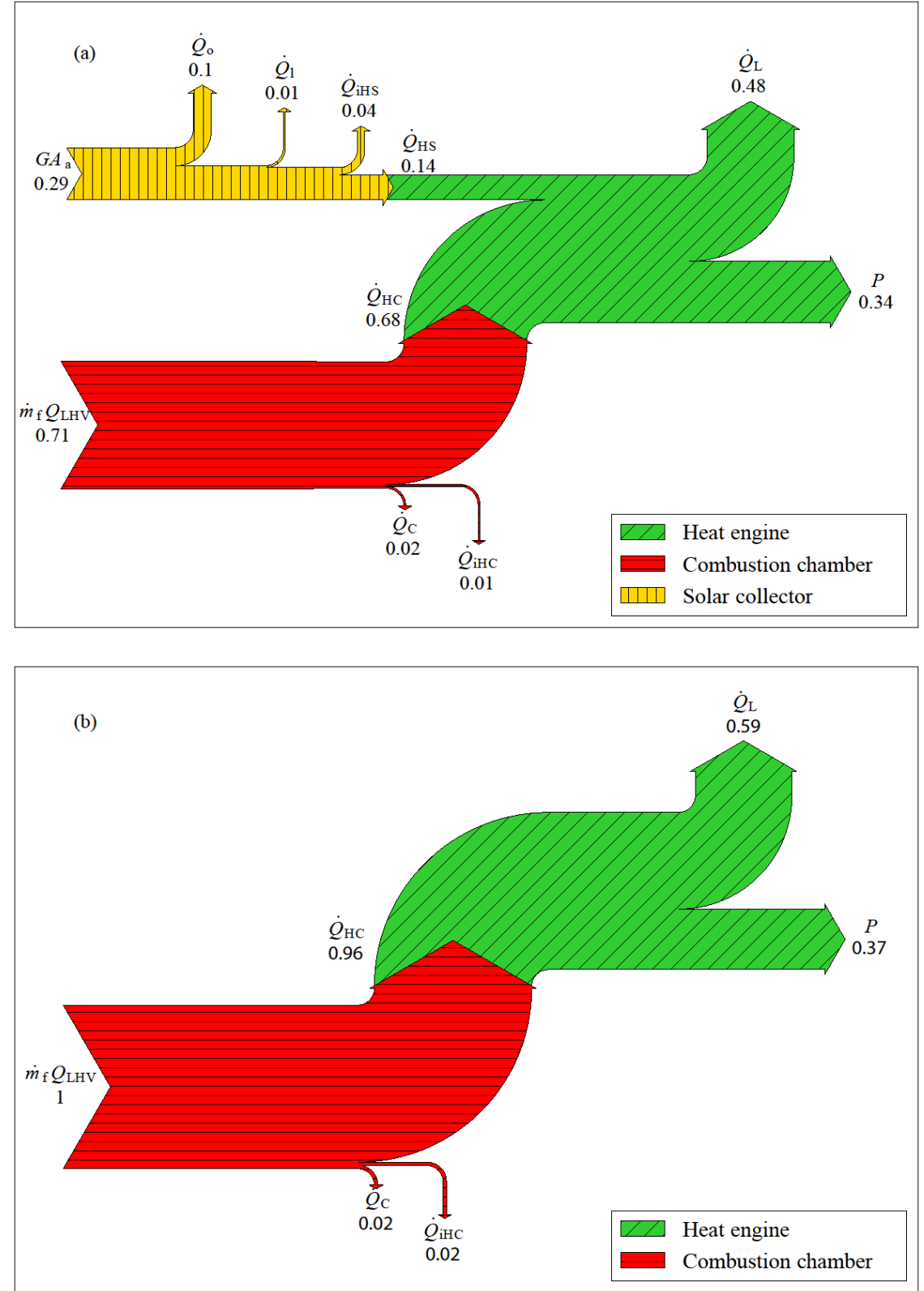

Fig. 5. Energy fluxes represented by means of Sankey's diagram in the plant with recuperation. Total energy input is normalized to unity. (a) Plant operation in hybrid mode. (b) Plant operation in pure combustion mode. 


\section{Conclusions}

A good way of visualizing thermal losses is by means of Sankey's diagrams, thus energy fluxes in the plant are plotted in Fig. 5, taking real yearly averaged solar irradiance and ambient temperature, and considering recuperation in the Brayton cycle. In this figure, energy fluxes have been normalized to unity with respect to the total energy input. Hybrid mode is represented in Fig. 5. (a), where it can be observed that the size of the solar input is small compared with the combustion one, which means that the assumed solar collector field is very small for the desired power output. This is a plant dimensioning problem, which is solved by reducing the power output supplied to the grid or by increasing the heliostat field. However, thermal losses in relative terms are quite larger for the solar subsystem. Likewise, optical losses represent about $10 \%$ of all the energy input.

Moreover, heat transfer losses in the solar field from radiation and conduction/convection add up approximately $1 \%$ and those in the solar receiver around $4 \%$. On the other hand, combustion chamber losses reach $1 \%$ and those of the associated heat exchanger are similar. In this way, the total heat input really released to the working fluid rounds $82 \%$ of the total input. Thus, the Brayton heat engine delivers a $34 \%$ of mechanical energy, although $48 \%$ is heat released to the ambient. This is the reason why a bottoming cycle could be a great idea, for example a Rankine one. This is an open work line for the next future.

Figure 5. (b) is related to pure combustion functioning, so, in this case, there is no solar subsystem losses and the power output is $37 \%$. Nevertheless, the heat released to the ambient reaches $59 \%$.

These kind of diagrams allow to locate and quantify losses, and also to analyze the thermodynamic margin for improvement for this technology.

In conclusion, our work provides, for a particular installation, how improvements in the plant equipment would affect the yearly averaged plant records. The performed sensitivity analysis implies that losses in turbine and compressor are what causes a worst effect in heat engine performance. So, overall plant efficiency and fuel conversion efficiency are quite more sensitive to improvements on the efficiency of the power unit components (compressor, turbine, recuperator, etc.). Additionally, it was shown that pressure losses in the heat absorption process especially affect power output records. On other hand, key parameters corresponding to solar subsystem are heliostat field optical efficiency and solar collector heat exchanger or receiver effectiveness. As a consequence, a reduction on optical losses substantially would decrease fuel consumption and, so, operation costs.

Interesting topics for future work concern the further development of the central receiver solar collectors, higher temperatures in combustion chambers and turbines, and also the possible utilization of working fluids as supercritical carbon dioxide or others [5].

Despite these plants are not economically profitable with the current technology, they are worth the effort from the ecological point of view, since they reduce pollutant emissions significantly, especially greenhouse gases. As a result, hybrid thermosolar plants help to mitigate anthropogenic intensification of climate change. So, this paper can help to lay the groundwork for a basic predesign of upcoming hybrid Brayton thermosolar power plants.

\section{Acknowledgement}

The authors acknowledge financial support from MINECO of Spain, Grant ENE2013-40644-R.

\section{References}

[1] O. Behar, A. Khellaf, K. Mohammedi, "A review of studies on central receiver solar thermal plants", in Rene. Sust. Energ. Rev., 23: 12-39, 2013.

[2] D. Olivenza-León, A. Medina, and A. Calvo Hernández, "Thermodynamic modeling of a hybrid solar gas-turbine power plant", in Energ. Conv. Manage., 93: 435-447, 2015.

[3] M.J. Santos, R.P. Merchán, A. Medina, and A. Calvo Hernández, "Seasonal thermodynamic prediction of the performance of a hybrid solar gas-turbine power plant", in Energ. Convers. Manage., 115: 89-102, 2016.

[4] R. Korzynietz, J. A. Brioso, A. del Río, M. Quero, M. Gallas, R. Uhlig, M. Ebert, R. Buck, D. Teraji, "Solugas comprehensive analysis of the solar hybrid Brayton plant", in Sol. Ener. 135: 578-589, 2016.

[5] P. Kumar, P. Dutta, S. Srinivasa Murthy, K. Srinivasan, "Solar driven carbon dioxide Brayton cycle power generation with thermal compression", in Appl. Therm. Eng., 109: 854860, 2016. 